\title{
Mars slow to yield its secrets
}

\section{Scientists seek fresh approaches to deciphering red planet's history.}

\section{BY ALEXANDRA WITZE PASADENA, CALIFORNIA}

$\mathrm{T}$ hunderous applause greeted planetary cartographer Ken Tanaka of the US Geological Survey on 14 July as he unveiled a new geological map of Mars. A culmination of more than a decade of probing the red planet's geology and history with orbiters and rovers, it revealed that large areas of the Martian surface are more ancient than once thought.

But by the time the Eighth International Conference on Mars closed five days later, the mood was less celebratory and more introspective. Talks and presentations at the meeting in Pasadena, California, had covered major recent discoveries on Mars, and yet scientists found themselves asking the same questions they had been chasing for decades: when did Mars have water on its surface, and what happened to it? Did life ever exist there?

"There's a lot of knowledge and not so much understanding," says Phil Christensen, a Mars geologist at Arizona State University in Tempe. "The devil continues to be in the details."

The sustained programme of Mars exploration pursued by NASA and the European Space Agency has unquestionably yielded a bounty of discoveries. Satellites such as the Mars Reconnaissance Orbiter have watched dust storms envelop the planet and carbon dioxide at its poles freeze and thaw. Rovers such as Curiosity have closely analysed rocks to determine where and when Mars might have contained watery, life-friendly environments.

But a thorough, planet-wide understanding of Martian history remains elusive. "It reminds me of Earth science in the 1950s - lots of observations but no overarching breakthrough yet," says David Des Marais, an astrobiologist at NASA's Ames Research Center in Moffett Field, California.

Among other things, Mars researchers have found it increasingly hard to explain how the planet might have stayed warm and wet in its early history (see Nature 484, 153; 2012). Sprawling river channels and water-rich clay minerals suggest that water once coursed across the Martian surface. (Today the planet is essentially bone-dry, although water may occasionally seep across the surface or just beneath it.)

Mars experts struggled last week to reconcile their detailed geological maps with their inability to explain how water could exist for extended periods. If, billions of years ago, the Martian atmosphere had consisted mostly of carbon dioxide as scientists suspect, it would not have kept the planet warm enough for liquid water to exist for long periods of time. Mars instead might have been much like Antarctica today, with high-elevation areas that remain frozen even at the height of summer. "This is completely different than what we thought about before," says James Head, a planetary geologist at Brown University in Providence, Rhode Island.

Some modellers are still trying to figure out a way to make a warm and wet Mars work. Planetary scientist Ramses Ramirez, of Pennsylvania State University in University Park, proposes that volcanoes belched out enough hydrogen to help heat the atmosphere and allow liquid water to flow (R. M. Ramirez et al. Nature Geosci. 7, 59-63; 2014). Others invoke a temporary warming brought about by sulphur spewed from ancient volcanoes - but even that would not have kept the planet toasty enough for liquid water year-round, says Laura Kerber of the Pierre and Marie Curie University of Paris.

Fixing the disconnect could take time - and new technology. Planetary geologist Bethany Ehlmann of the California Institute of Technology in Pasadena says that the next generation of instruments to explore Mars should be able to probe rocks in extreme closeup. Her ideal gadget would be a high-resolution camera combined with a spectrometer that could gather information on minerals in the rock in unprecedented detail. Such close-up analysis could reveal more-precise information to help to unravel the history of a particular rock, how it formed and what that might say about past environments, she says.

Also on Ehlmann's wish list: a way for future rovers to measure the precise ages of rocks on the Martian surface. "The more age-dating, the better," she says. "We have to get at these questions of timing." For now, almost all dates for Martian rocks are relative, obtained by looking at how extensively rock formations have been beaten up by impacts - researchers assume that the more pummelled ones have been around longer. Chemical analysis could provide a much more precise age, allowing scientists to tease out the sequence of events in Martian history.

Neither of Ehlmann's goals will be addressed by the next few spacecraft going to Mars: a NASA geophysical probe launching in 2016, and a European orbiter in 2016 and rover in 2018. In the next few weeks, NASA is expected to announce what instruments will be aboard a rover due to launch in 2020, the first step towards gathering samples to be left on the surface for possible future return to Earth (see Nature 509, 272; 2014).

Mars researchers should not be discouraged by the slow progress so far, says Jean-Pierre Bibring, a planetary scientist at the University of Paris-South. The very fact that there are so many data to argue about is a huge step forward, he told the meeting: "It's a dramatic revolution we're in now." - 